\title{
A critical review of experimental observations on eardrum structure and function
}

\author{
W. Robert J. Funnell \& Charles A. Laszlo \\ BioMedical Engineering Unit \& Department of Otolaryngology \\ McGill University \\ Montréal, Québec, Canada H3G 1Y6 \\ Submitted to ORL, July 1978 \\ Revised, August 1981
}

Summary. This paper presents a review of the experimental data available concerning eardrum structure, properties and behaviour, in order to provide a basis for quantitative modelling and to identify areas where further information is required. The review of anatomy and structure indicates a lack of quantitative data about thickness, fibre distribution, three-dimensional curvature, and post-natal development. The mechanical properties of the ear-drum and attached structures are very poorly known, particularly with respect to isotropy, uniformity and damping. A historical review of observations of ear-drum vibration patterns shows general agreement that at low frequencies the displacements of the manubrium are smaller than those of the surrounding drum. Possible reasons are suggested for the apparent incompatibility of Békésy's capacitive-probe measurements with this picture.

Keywords - tympanic membrane, mechanical properties, vibration, middle ear, comparative anatomy

\section{INTRODUCTION}

Presently available models of the external and middle ear do not provide us with a very satisfying understanding of the system. The weakest aspect of these models seems to be their representation of the eardrum, which is simplified to the point of obscuring essential features. This paper is a review of the experimental data available concerning, eardrum structure, properties and behaviour. The goal is to identify areas where further information is required if we are to have a firm basis for mathematical modelling. As well as serving as a formalization of our understanding of the system, such modelling would hopefully permit the quantitative analysis of pathological conditions as an aid to planning and evaluation of diagnostic or corrective techniques.

The following Section will discuss selected features of the gross and microscopic structure of the eardrum, with the emphasis on mammalian ears intended for the reception of air-conducted sound; the review is far from exhaustive. Sections 3 and 4 will discuss what little is known about the mechanical properties of the eardrum and surrounding structures. Section 5 will then present a review of experimental observations of eardrum vibration patterns.

\section{STRUCTURE OF THE EARDRUM}




\subsection{Gross Anatomy}

Tympanic ring and manubrium. The comparative gross anatomy of the middle ear has been described by a great many authors. \{Fumagalli (1949)\} and $\{$ Fleischer (1973)\} have published particularly extensive accounts.

The typical mammalian eardrum consists basically of a very thin sheet of connective tissue (pars tensa). The annular ligament firmly anchors it to bone around most of its circumference, and the manubrium of the malleus is tightly coupled to it. The outline of the pars tensa varies in different species from more or less circular to a somewhat elongated ellipse. The manubrium may be placed symmetrically, or it may be somewhat closer to the anterosuperior edge of the pars tensa. The significance of these variations is unclear.

The pars flaccida is a less important (and more elastic) part of the drum surface, superior to the manubrium and separated from the pars tensa by the annular ligament. The size of the pars flaccida is very variable: it is very large in the sheep and mouse, and absent in the guinea pig. In man and cat it is moderately small. In some specialized rodents (among the Dipodidae and Gerbillinae) an accessory tympanic membrane (Hyrtl's) is found. Its position is similar to that of the pars flaccida, but structurally it is the same as the pars tensa. It may contribute significantly to the middle-ear transformer (\{Lay, 1972\}, p. 57) and it deserves further study.

The size of the eardrum tends to vary less from species to species than does overall body size. \{Khanna \& Tonndorf (1969)\} demonstrated that a linear dimension of the eardrum (square root of the area) is approximately proportional to the square root of a linear dimension of the whole body (i.e., of the cube root of weight) among seven diverse mammalian species. Hunt \& Korth (1980)\} calculated a regression line with a slope of 0.26 relating the logarithm of eardrum area to the logarithm of body weight among 40 mammalian species; this corresponds to an exponent of about 0.4 when comparing linear dimensions, close to the value of 0.5 of Khanna \& Tonndorf. The size of the rest of the middle ear is generally comparable to that of the eardrum. \{Webster \& Webster (1975)\}, for example, have shown that among one group of rodents a linear dimension of the eardrum is approximately proportional to a linear dimension (cube root of the volume) of the 
middle-ear cavity. In fact, the values for the cat and guinea pig fall quite close to the same straight line.

A parameter which is of considerable interest in discussions of middle-ear function is the ratio of the area of the eardrum to that of the oval window, since this is the largest single factor contributing to the middle-ear transformer ratio. Figure 1 displays this ratio plotted against drum area for a number of mammalian species. The semi-aquatic and burrowing species all have a similar area ratio in spite of the range in body size and the phylogenetic diversity. The ratio is small, presumably reflecting the relative unimportance of air-borne sound to these species. The ungulates and rodents are both large, diverse families, and this diversity shows in the spreads in both the area and ratio data. Most of the carnivores have moderately high area ratios, while the ratios of the primates tend to be somewhat lower. The insectivores and bats all have small eardrums and relatively high area ratios, suggestive of good high-frequency sensitivity.

Note that a number of authors have attempted to draw conclusions from this sort of comparison of area ratios, anatomically measured ossicular lever ratios, and so on ( $\{$ Webster, 1966\}; \{Oaks, 1967\}; \{Lay, 1972\}; $\{$ Fleischer, 1973\}; \{Peterson et al., 1974\}; \{Webster \& Webster, 1975\}; \{Hunt \& Korth, 1980\}). Some of these have attempted to refine the measures by, for example, correcting the eardrum-area parameter for the effect of the conical shape of the drum, and have calculated transmission efficiencies for the middle ear. Apart from the question of whether the conicalness is relevant to the matter of efficiency, a more fundamental question is whether these estimates of efficiency are likely to be meaningful in view of the great simplifications involved. The operation of the middle ear is affected by a number of factors (such as external ear-canal shape, eardrum curvature, the mode of vibration of the eardrum, the nature of the ossicular suspension and muscles, and the

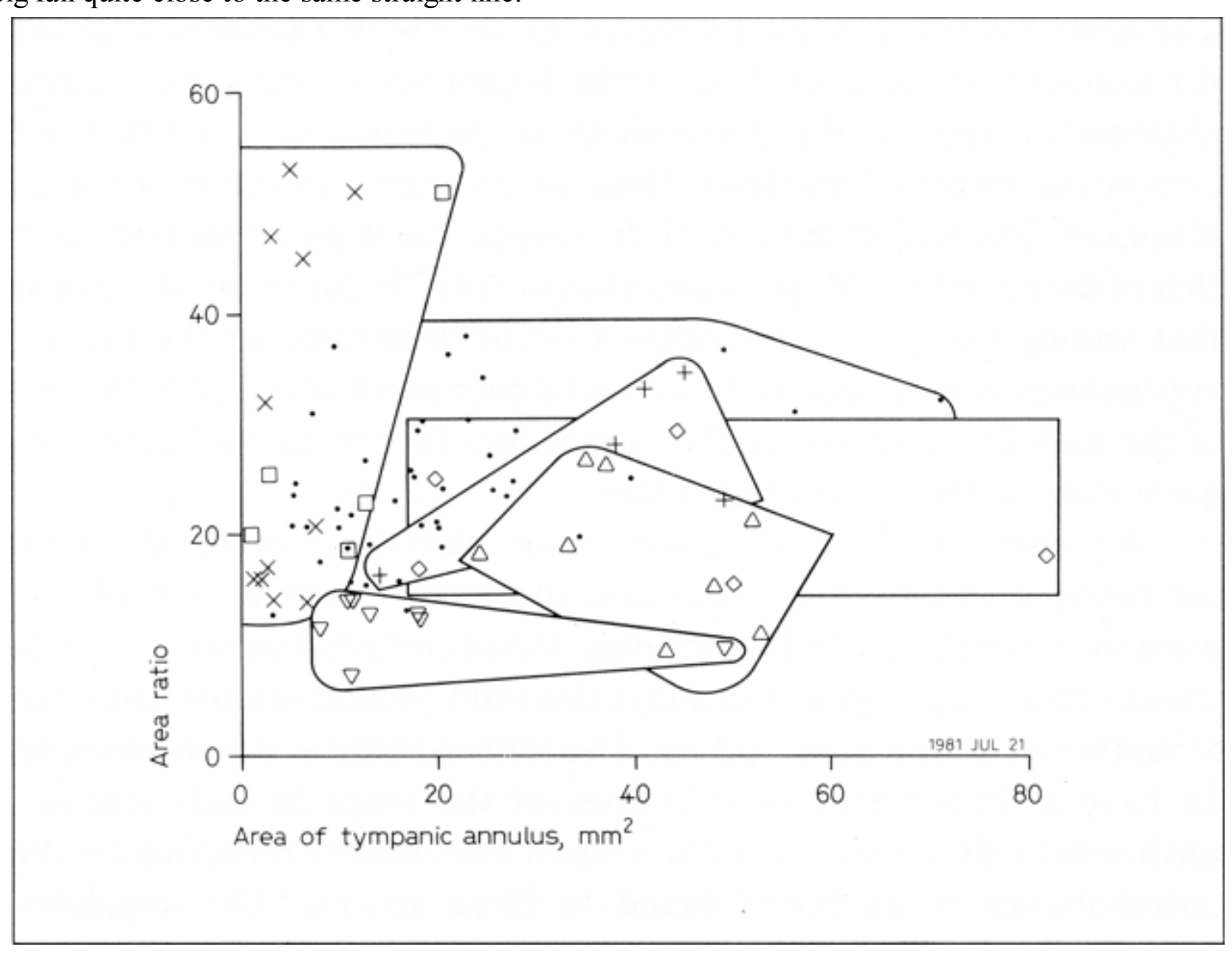

Fig. 1. Area ratio (area of tympanic annulus over area of oval window) plotted against area of tympanic annulus for various mammalian species. Note that the areas are those enclosed by the tympanic annulus, rather than the actual surface area of the conical drum. Some of the rodent points are derived from data in Oaks [1967], Peterson et al. [1974], and Webster and Webster

[1975a,b]. The rest of the data are from Kirikae [1960], or from Fleischer [1973] as tabulated by Hunt and Korth [1980]. • = 
ossicular load) about which little or nothing is known in most species. It is noteworthy that most of these attempts have applied a correction factor of $2 / 3$ to the area of the eardrum; this factor is based on eardrum vibration measurements ( $\{$ Békésy, 1941\}) which are no longer accepted as valid (see Section 5 below).

Conical shape. The mammalian eardrum is approximately conical, with the apex pointing medially. \{Fumagalli (1949)\} found that the eardrum shapes of all of the nine species he observed could be represented approximately by a cone with an apex angle of $120^{\circ}$, cut at various angles by the plane of the tympanic ring. The guinea-pig drum was a right cone, but the others all showed some degree of obliquity, correlated with the angle of the manubrium mentioned in the previous section.

Curvature. The sides of the cone formed by the eardrum are convex outward. There are no reliable and precise data in the literature concerning the actual curvature of the drum. $\{$ Kojo (1954)\} and \{Kirikae (1960)\} studied paraffin castings of the human drum, but their published accounts are sketchy and their data were probably distorted by the casting process. Kirikae also measured the angle included in the apex of the curved cone formed by the eardrum in each of several species, but reported only that it "ranged from $97^{\circ}$ for Barbary sheep to $135^{\circ}$ for the mole and squirrel in mammals". He noted that the ungulates and carnivora had relatively small apex angles and generally had long manubria (compared to the diameter of the drum) while other animals, with larger apex angles, had short manubria with the umbo located near the centre of the drum. More recently, \{Khanna \& Tonndorf (1975a,b)\} have used moiré topography (an optical technique) to study the three-dimensional shape of the cat eardrum using a refined casting technique.

The curvature of the eardrum described above is apparently universal among terrestrial mammalian eardrums. Even in the Monotreme platypus, which in many ways is a very primitive mammal, and in which the middle and inner ear shows many differences in detail from the mammalian norm, the eardrum has the normal curvature (judging from Figure 1 of \{Gates et al., 1974\}). The echidna, the only other living Monotreme, does not appear to have a typically curved drum, but here the gross mechanical behaviour of the entire middle ear is unusual ( $\{$ Aitkin \& Johnstone, 1972\}).

Thickness. There are not many detailed data available concerning eardrum thickness. \{Kojo (1954)\} measured the thickness at seven locations on each of seven human eardrums: the total range was from 30 to $120 \mathrm{um}$, with the average values for the seven locations ranging from 55 to 90 um, the smallest values being in between the periphery and the manubrium. By comparison, $\{\operatorname{Lim}(1970)\}$ reported that the human eardrum varies in thickness from 30 to 90 um. The cat drum is 30 to 50 um thick, and the guinea-pig drum is about 10 um thick (\{Lim, 1968a) $\}$. More detailed measurements are required on variations of over-all thickness across the surface of the drum, and also on the thicknesses of the constituent layers discussed below.

\subsection{Microscopic Structure}

Introduction. The pars tensa is composed of three layers: an outer epidermal layer; the lamina propria, consisting of two connective-tissue layers and a fibrous layer; and an inner mucosal layer. The pars flaccida is much the same as the pars tensa except that it lacks the highly organized layers of the lamina propria, and contains a higher proportion of elastic fibres compared to inelastic (collagen) ones ( $\{\mathrm{Lim}, 1968 \mathrm{~b}\})$. It is usually small, and because of its greater elasticity has little effect on the vibration of the eardrum. It has been suggested that the pars flaccida may serve to equalize small static pressure differences between the ear canal and the middle-ear cavities ( $\{$ Wilber, 1976\}, p. 53).

The following paragraphs describe the structures of the three layers of the pars tensa, based mainly on studies of human, cat and guinea-pig eardrums.

Epidermal layer. This layer is continuous with the epidermis of the external ear canal, and is quite similar to epidermis found elsewhere on the body ( $\{$ Wilkes 
et al., 1973\}). The epidermis of the eardrum and of the deepest (bony) part of the external ear canal is somewhat specialized: it does not contain any glands or hair follicles (\{Johnson et al., 1968\}; \{Reijnen \& Kuijpers, 1971\}) as does other skin. It also shows powers of lateral migration not encountered in epidermis elsewhere (\{Magnoni, 1938\}; \{Alberti, 1963, 1964\}; \{Litton, 1968\}; \{Boedts \& Kuijpers, 1978\}): the drum epithelium constantly migrates outward from the centre of the drum as new cells are formed, desquamating only when it reaches the cartilaginous portion of the ear canal. The process accounts for the self-cleaning ability of the ear canal.

The outermost layer of the epidermis, the stratum corneum, is very dense. Although very thin, it is possible that it has some effect on the mechanical properties of the eardrum.

Mucosal layer. The mucosal layer of the eardrum is a continuation of the mucosal lining of the middle-ear cavity. It is a very thin layer of cells and presumably has no mechanical function.

Lamina propria. The subepidermal and submucosal loose connective-tissue layers of the lamina propria contain abundant collagen fibrils held in a considerable volume of ground substance. There are a few elastic fibres near the pars flaccida. The collagen fibres are described as "irregularly arranged" (\{Lim, 1970 $\}$ ) and "loose" ( $\{\mathrm{Lim}, 1968 \mathrm{a}\})$, but in some photomicrographs ( $\{\mathrm{Lim}, 1970\}$, Figure 3a; $\{\mathrm{Lim}, 1968 \mathrm{a}\}$, Figure 4a) there does seem to be a dominant direction. This organization is presumably only local. These connective-tissue layers probably have little effect on the behaviour of the eardrum.

The main structural components of the eardrum are the highly organized radial (outer) and circular (inner) fibre layers. They consist of parallel arrays of fibres in a relatively scanty matrix of ground substance. The radial fibres generally run more or less straight from the manubrium to the annular ligament, although some curve before reaching the latter ( $\{$ Shimada \& Lim, 1971\}, for example). The fibres become more closely packed as they converge on the manubrium. In the upper third of the manubrium the radial fibres cross the lateral face of the manubrium and wrap part-way around before inserting, while lower down the anterior radial fibres change pattern and wrap around the medial face of the manubrium ( $\{$ Fumagalli, 1949\}). In man the attachment of the pars tensa is less direct in the upper portions of the manubrium than it is in the lower third ( $\{$ Politzer, 1889\}, Figures 138-141; $\{$ Graham et al., 1978\}).

The circular fibres start from the manubrium, curve around below the umbo, and insert again on the opposite side of the manubrium. Most of them are attached to the manubrium fairly close to the upper end, near the short process. The circular-fibre layer is less well developed than the radial-fibre layer, and near the centre of the drum is very thin or even absent. It grows thicker toward the periphery. \{Helmholtz (1869)\} quoted two earlier authors (Gerlach, Gruber) as stating that it is absent or very thin at the extreme periphery, but $\{$ Gruber (1867)\} at least was apparently just alluding to the fact that few circular fibres actually enter the tympanic annulus.

Between the two layers is a thin layer of oblique fibres. The detailed descriptions of this layer differ between authors and between species, and the fibres have at various times been called parabolic, crescentic and transverse. Although \{Fumagalli (1949)\} ascribed a functional significance to these fibres, at least in some species, it would seem that they are too few to be of major importance. There are also a few radial fibres on the medial surface of the circular-fibre layer, which presumably are not very important. \{Shimada \& $\operatorname{Lim}(1971)\}$ reviewed the status of these miscellaneous fibre systems.

The fibres of both the radial and circular layers are composed of some typical collagen fibrils (diameters on the order of $50 \mathrm{~nm}$ ) mixed with large numbers of finer fibrils (about $5 \mathrm{~nm}$ square, apparently composed of four sub-units). In the guinea pig, none of the larger fibrils are found at all (\{Lim, 1968a $\}$ ). In man, the proportion of the finer fibrils compared to the larger ones is greater in the radial fibres than in the circular fibres ( $\{$ Lim, 1970\}). The nature of the finer fibrils is not known. They do not show the 65-nm banding typical of collagen (caused by a very regular alignment as the 1.5-nm-diameter, 300-nm-long molecules combine 
to form filaments and fibrils). On the basis of an amino-acid analysis, \{Johnson et al. (1968)\} suggested that they are neither collagen nor elastin: their amino-acid composition shows some of the features of both. Other authors have suggested that they are keratin or reticulin, two other fibrous proteins (see \{Lim, 1970$\}$, for discussion). They could also be a form of collagen whose supramolecular structure is not sufficiently regular to display banding. The composition of collagen can vary considerably from tissue to tissue, and between species (see, for example, \{Dayhoff, 1972\}; \{Stenzel et al., 1974\}).

\subsection{Ontogenesis of the Eardrum}

There have been many descriptions of the embryological developmen of the middle and external ear (see $\{$ Bowden, 1977\}, for a recent review) but there remain questions about the age at which the eardrum and middle ear are functionally mature. In the mouse (\{Mikaelian \& Ruben, 1965\}), kangaroo rat ( $\{$ Webster, $1975\})$ and hamster ( $\{$ Relkin et al.,1979\}; \{Relkin \& Saunders, 1980\}) it appears that development continues for the first few weeks after birth. The human middle ear, although possibly containing amniotic debris (\{deSa, 1977\}) or fluid at birth, appears to be functioning well within hours $(\{$ Keith, 1975 $\})$ or days ( $\{$ Taguchi et al., 1969\}) after birth.

It is known that the middle ear as a whole continues to change long after birth in the human ( $\{$ Diamant, 1940 $\})$ and in the guinea pig ( $\{$ Funnell \& Laszlo, 1974$\})$. The functional significance of this is not known, nor is it clear to what extent the eardrum takes part in the on-going development. $\{$ Zanzucchi (1938) $\}$ reported that in man the system of elastic fibres around the periphery, and at the insertion of the malleus, does not form until after the first year of life, and that it continues to develop thereafter. $\{$ Filogamo (1943)\} found that the only postnatal modification was a very slight increase in fibre diameter, and $\{$ McMinn \& Taylor (1978)\} did not mention even that.

\subsection{Evolutionary Trends}

There are some trends in the evolution of the microstructure of the vertebrate eardrum which are of uncertain significance but which are suggestive. After the amphibians, collagenous and non-radial fibres were mixed in with the radial elastic ones, the type of coupling to the ossicles was changed, and the muscle cells and tendons were gradually removed from the surface of the drum (\{Filogamo, 1949\}). After the reptiles, the drum became strongly conical. The mammals are peculiar in having lost all of the elastic fibres, and in having the radial and circular fibres completely separated into two different layers.

With respect to the fact that both birds and mammals have conical drums, albeit pointing in opposite directions, it is interesting to note that $\{$ Gaudin (1968)\} has suggested that birds also have an effective ossicular lever, implemented differently than the mammalian one is. From one of his illustrations, it would appear that the avian drum also has sides that are curved and convex towards the interior of the cone.

\section{MECHANICAL PROPERTIES OF THE EARDRUM}

\subsection{Introduction}

This section reviews the gross mechanical properties of the eardrum that determine its vibratory behaviour. The questions of whether these properties are isotropic (i.e., the same in all directions) and uniform (the same in all locations) have been treated by $\{$ Békésy $(1941,1949)\}$ and $\{$ Kirikae (1960)\}, but it is difficult to draw quantitative conclusions at this point (\{Funnell, 1975\}). 


\subsection{Stiffness}

\{Békésy (1949)\} measured the bending stiffness of the human cadaver eardrum by cutting out a rectangular flap ( $2 \mathrm{~mm} \mathrm{x} 0.5 \mathrm{~mm})$ along three sides. He applied a pre-calibrated force to the free end and measured the displacement to be $50 \mathrm{um}$. Assuming the flap to be a uniform, isotropic cantilevered beam, he used a standard formula from mechanics to calculate an elastic modulus of $2 \times 10^{8} \mathrm{dyn}^{-2}$. He stated that the elastic coefficient is about the same in the guinea pig, presumably on the basis of similar measurements. It appears that the displacements were probably within the linear operating range of the collagen fibres ( $\{$ Funnell, 1975\}).

\{Békésy (1949)\} also measured the stiffness of the calf eardrum, using a somewhat different technique, and arrived at an elastic modulus that was smaller than the human one by a factor of $10^{4}$. This result is suspect because of the theoretical analysis used and because of the apparent abnormality of the eardrum studied $(\{$ Funnell, 1975\}).

\{Kirikae (1960)\} measured the stiffness of a strip of human eardrum (10 mm x $1.5 \mathrm{~mm}$ ) weighted at one end and vibrating longitudinally at $890 \mathrm{~Hz}$. He calculated a Young's modulus of $4 \times 10^{8} \mathrm{dyn}^{-2}$, based on a drum thickness of $75 \mathrm{um}$. Taking the thickness as 50 um, as Békésy did, would have given a modulus of $6 \times 10^{8} \mathrm{dyn}^{-2}$. These values are two and three times stiffer than Békésy's, respectively. Kirikae reported that he obtained the same results when the weight hanging from the eardrum strip was varied from $300 \mathrm{mg}$ to $1000 \mathrm{mg}$, indicating linearity.

Recently some measurements were made on a few strips of human eardrum (3-5 mm x 2-4 mm) driven by an electromagnetic driver at frequencies up to 100 to $300 \mathrm{~Hz}(\{$ Decraemer, 1980c $\})$. An effective Young's modulus of about $2 \times 10^{8} \mathrm{dyn}^{-2}$ was obtained, in good agreement with Békésy's measurement.

In using these results one must keep in mind the facts that (1) the measurements were made on relatively large strips of eardrum with unspecified and nonuniform fibre distributions; (2) the results include the unknown contributions of the nonfibrous layers of the eardrum; (3) the thickness of the drum is variable and difficult to measure; (4) one experiment involved transverse displacements while the other two involved longitudinal displacements; (5) the dependence of the stiffness on frequency is unknown; and (6) the effects of post mortem conditions, including lack of blood supply and altered temperature and humidity, are unknown ( $\{$ Funnell, 1975\}).

It is interesting to compare the elastic moduli measured in the eardrum with that of collagen. If one uses an effective thickness equal to that of the combined radial and circular layers (33 um in $\{\mathrm{Lim}, 1970\}$, Figure 4), instead of the total drum thickness, one should obtain a value for Young's modulus corresponding to the fibres themselves (assuming that they dominate the eardrum's mechanical properties). On this basis, Békésy's data yield a modulus of $7 \mathrm{x} 10^{8} \mathrm{dyn} \mathrm{cm}^{-2}$. Using the thickness of either the radial or circular layer alone would raise the value further, as would the use of Kirikae's data. It is interesing to compare this elasticity to values measured for other collagenous tissues. \{Haut \& Little (1969)\} found a stiffness of 10 to 20 x $10^{8} \mathrm{dyn}_{\mathrm{cm}} \mathrm{c}^{-2}$ for an "almost entirely collagenous" ligament when the strain was high enough that the fibres were being stretched rather than just re-oriented. Under similar conditions, \{Grahame (1970)\} found a stiffness of $10^{8}$ to $10^{9} \mathrm{dyn}^{-2}$ for human skin in vivo (with considerable individual variation as well as dependence on age and sex). These figures are quite similar to the values measured for the eardrum. Even though the fibres of the eardrum may not be collagen, or at least not ordinary collagen (as discussed above), their mechanical properties appear to be similar to those of collagen. (For the purposes of comparison, consider the Young's moduli of the following materials: $10^{7}$ dyn $\mathrm{cm}^{-2}$ for smoked rubber ( $\{$ Kirikae, 1960$\left.\}\right) ; 8 \times 10^{10} \mathrm{dyn} \mathrm{cm}^{-2}$ for pine wood (\{Békésy, 1949\}); and $2 \times 10^{12} \mathrm{dyn}^{-2}$ for steel.) 


\subsection{Poisson's Ratio}

Poisson's ratio is the ratio of transverse to axial strain when a material is submitted to uni-axial stress. It has never been measured for the eardrum. For common materials it ranges from about 0.3 , for isotropic crystalline solids, to 0.5 for rubberlike materials ( $\{$ Snowdon, 1968\}). For a material composed of parallel fibres with no lateral interaction among the fibres, Poisson's ratio would be zero for a stress applied in the direction of the fibres. Since there are no experimental data to decide the issue, one might assume a value of 0.3 for the Poisson's ratio of the eardrum, as a compromise. The behaviour of the eardrum is probably not very sensitive to the value of Poisson's ratio ( $\{$ Funnell, 1975\}).

\subsection{Tension}

The only attempts that have been made to evaluate the degree of tension in the eardrum are those of \{Békésy (1949)\} and \{Kirikae (1960)\}. Békésy cut out U-shaped flaps in the eardrum. In the calf and sheep the flaps shrank and the cut-out hole expanded, which he interpreted as evidence of tension. The shrinkage and expansion occurred very slowly (over about 10 seconds), which Békésy thought was due to a large viscosity in the drum; it might also indicate that the dimensional changes were a result of tissue distortion along the cut edges, rather than tension release. In any case, the flaps apparently did not shrink in the human and guinea-pig drums, since he stated that they were not under tension.

Kirikae investigated the tension by cutting slits about $0.5 \mathrm{~mm}$ long at various positions and orientations on human cadaver eardrums, both with and without removing the epidermal layer. The only slits that became enlarged (to about $0.1 \mathrm{~mm}$ wide), suggesting tension, were those cut perpendicular to the radial fibres with the epidermis removed. Kirikae interpreted these results as merely confirming Békésy's finding that the eardrum's properties are uniform and isotropic. If the spreading of the slit really indicates tension, however, then Kirikae's observations indicate that the radial fibres are under more tension than the circular ones, and that the epidermis is able to prevent the radial fibres from shrinking when their tension is released.

It is uncertain that tests such as the above are sensitive enough to detect tension in the eardrum. If one assumes that the resting tension in the eardrum is comparable to the tension that can be developed by the tensor tympani, then one can calculate that the amount of radial-fibre stretch to be released by a slit is on the order of 25 um ( $\{$ Funnell, 1975\}). For a short slit the release would be less because of the restraints imposed by neighbouring fibres. An enlargement of a slit or flap by 25 um would be difficult to detect, and might indeed be caused by local structural damage in the act of cutting.

The fact that Békésy's and Kirikae's experiments were done on cadaver ears obviously means that they could not detect any component of eardrum tension due to tonus in the tensor tympani. Also, any tension maintained passively by the ossicular ligaments might be sensitive to post-mortem tissue changes.

$\{$ Helmholtz (1869)\} believed that the curvature of the eardrum was maintained by a tension working against the circular fibres. That the curvature cannot all be explained as due to resting tension is indicated by the observation that a completely detached human eardrum, after being "rolled up, ... unfolds itself rapidly under water, and displays its exact contours" (\{Politzer, 1889\}, p. 76). At the moment all that can be said is that there is no good evidence for resting tension in the eardrum.

\subsection{Internal Damping}

Little attention has been paid to vibration damping in collagenous tissue. \{Witnauer \& Palm (1961)\} estimated the internal resistance of leather from the width of 
the resonance in their measurement of the dynamic modulus of elasticity. The ratio of the modulus of elasticity to the internal resistance was found to be about $10^{3} \mathrm{sec}^{-1}$ at their observed resonance frequency of 15 to $20 \mathrm{~Hz}$. Consistent with this, recent measurements in strips of eardrum suggest that the internal damping is unimportant at least up to $300 \mathrm{~Hz}$ ( $\{$ Decraemer, 1980c $\})$.

\subsection{Density}

The eardrum probably has a more or less constant volume density, somewhere between that of water $\left(1.0 \mathrm{~g} \mathrm{~cm}^{-3}\right)$ and that of undehydrated collagen $\left(1.2 \mathrm{~g} \mathrm{~cm}^{-3}\right.$ $(\{$ Harkness, 1961\})). The epidermal, mucosal and loose connective-tissue layers are probably less dense than the fibrous layers.

\section{PROPERTIES OF STRUCTURES SURROUNDING THE EARDRUM}

\subsection{Annular Ligament}

The radial fibres of the eardrum, and some of the non-radial ones, extend into the annular ligament around the periphery of the pars tensa. This ligament is a fibrous thickening firmly attached to a sulcus in the bony tympanic ring, except superiorly where it separates the pars tensa from the pars flaccida. \{Longo (1962)\} has described in some detail how the shape and depth of the sulcus vary around the circumference of the drum, and how collagen fibres from the annular ligament invade the tympanic ring to different extents in different regions.

Although these variations affect the response of the eardrum to gross mechanical disruptions, from the point of view of acoustical vibrations the drum may presumably be considered to be rigidly attached to the tympanic ring around its entire circumference. That is, drum displacements are zero at the ring. Whether the spatial derivative of the displacement is zero there is less clear. The distinction is between behaviour like a fully-clamped cantilevered beam and behaviour like a hinged beam. From drawings showing the insertion of the eardrum into the annular ligament (see, for example, \{Politzer, 1889\}, Figure 135; RRuttin, 1921\}; and $\{$ Filogamo, 1943\}, Figure 16) one gets the impression that the boundary of the eardrum is fully clamped to the annular ligament and thence to the bony ring. The fact that there are elastic fibres in the ligament, and in the drum itself near the ligament, might however provide enough flexibility that the boundary should be considered to be hinged. (As discussed in $\{$ Funnell (1975)\} it is not justified to say (\{Gran, 1968\}) that $\{$ Békésy (1949)\} assumed a fully clamped condition.) The actual situation is probably somewhere between these two idealized extremes, and it appears that the effect on eardrum behaviour is small in any case ( $\{$ Funnell, $1975\})$.

\subsection{Manubrium}

The manubrium behaves as a rigid rod, at least by comparison with the eardrum ( $\{$ Khanna, 1970 $\}$ ). It is much stiffer than the latter both because it is bone and because it is much thicker. As for the question of whether the eardrum is hinged or fully clamped at the manubrium, much the same considerations apply as in the preceding section.

As noted above, the fibres of the eardrum are not directly inserted into the middle third of the manubrium, at least in the human. $\{$ Tonndorf \& Khanna (1972) $\}$ noted that the drum and manubrium did not seem to be so tightly coupled in this region, although the effect was quite small. 


\subsection{Ossicular Load}

The effective load exerted on the eardrum by the ossicular chain has often been modelled using lumped-parameter circuit theory ( $\{$ Onchi, 1961\}; $\{$ Zwislocki, $1963\}$; $\{$ Peake \& Guinan, 1967\}; \{Lynch, 1981\}; and many others). Attempts have been made to estimate the parameters corresponding to the ossicles by studying the results of various experimental manipulations such as interrupting the incudomalleolar joint, opening the cavities widely, and so on. The interpretation of these results depends heavily on the model used, however. The representation of the eardrum has been particularly weak in these models, making it difficult to separate the effects of the ossicular chain from those of the drum itself. Attempts to estimate the mechanical properties of the ossicles and middle-ear ligaments based on their geometries ( $\{$ Funnell, 1975\}; \{Funnell \& Laszlo, 1978\}) have been crude at best.

It should be noted that practically all of the middle-ear modelling that has been done so far has concerned either the cat, human or guinea-pig ear. The configuration of the malleus and incus is different in each of these three species, but they are all similar in that the malleus and incus are suspended from the skull by ligaments, and the axis of rotation of the malleoincudal complex is more or less perpendicular to the manubrium. None of them displays the arrangement that has been described as being the primitive mammalian condition in which the malleus is firmly fused to the tympanic bone, forming an apparent axis of rotation parallel to the manubrium. ( $\{$ Henson, 1961\}; \{Hopson, 1966\}; \{Fleischer, 1973, 1978\}). It has been suggested (\{Fleischer, 1974\}) that there are actually two possible axes of rotation in this configuration, one parallel to and one perpendicular to the manubrium. There is some recent experimental evidence that this is in fact the case in the mouse, with a transition from a low-frequency parallel axis to a high-frequency perpendicular one, but that the latter mode may not be functionally important ( $\{$ Saunders, 1981\}).

\subsection{Cochlear Load}

The load that the cochlea presents to the ossicular chain (and thus indirectly to the eardrum) has been measured experimentally in the cat ( $\{$ Lynch et al., 1976\}). The extrapolation of this data to estimates of the cochlear load in other species is almost pure guesswork.

\subsection{Middle-Ear Air Cavities}

The effects of the middle-ear air cavities on the vibration of the eardrum, at least at frequencies low enough that they exert a practically uniform pressure, have been analyzed quite thoroughly in cat, guinea pig and human (\{Mundie, 1962\}; ZZwislocki, 1962, 1963\}; PPeake \& Guinan, 1967\}; Funnell, 1972\}; Lynch, $1981\})$. The radiation impedance of the air surrounding the eardrum has generally been neglected, although it has been considered in studies of insect ears ( $\{$ Michelsen, 1971\}; \{Michelsen \& Larsen, 1978\}).

\section{EXPERIMENTAL OBSERVATIONS OF EARDRUM VIBRATIONS}

\subsection{Introduction}

This section is a review of previously published observations of normal eardrum vibration patterns. Most of these observations have been at low frequencies, that is, zero to 1 or $2 \mathrm{kHz}$ : the eardrum's mode and amplitude of vibration are essentially constant over this frequency range. These observations are discussed in approximately chronological order below, with higher-frequency data discussed separately. Only work which attempted to measure spatial patterns of eardrum 
vibration is discussed, and studies which reported only observations of single points or of overall impedance are explicitly excluded. Also excluded are a few observations of pathological eardrums (\{Tonndorf et al., 1971,1972\}; \{Helms, 1974, 1977\}).

Note that all of the experimental work discussed below concerns species in which the malleus and incus are suspended by ligaments. So far no observations of eardrum vibration patterns have been made in ears with the malleus fused to the tympanic bone (except for the observations in rat by $\{$ Helms, 1977$\}$, about which no details were given).

\subsection{Low-Frequency Vibration Pattern}

Visual observations I. $\{$ Kessel (1874) \} reported direct visual observations of eardrum displacements due to static pressures in human cadaver ears, using a simple magnifying lens. With respect to the pars tensa, he found that under a positive pressure in the ear canal the eardrum moved inwards and the curvature of the radial fibres flattened; under a negative pressure the curvature increased. The greatest displacements were seen in the posterior segment of the drum. Kessel also used a stroboscope to observe vibrations at $256 \mathrm{~Hz}$ and $512 \mathrm{~Hz}$, again using a magnifying lens. Again the displacements were larger posteriorly, although in this case he said that the greatest displacements occurred in the central region of the drum where there are no circular fibres. The pressure used in these experiments was about 155 dB SPL. \{Mach \& Kessel (1874)\} mentioned taking some measurements at a pressure about 6 dB less.

$\{$ Lucae (1901)\} also observed eardrum vibrations visually under stroboscopic illumination. The stimuli were air-pressure variations with unspecified amplitudes and poorly defined waveforms (see figures in $\{$ Lucae, 1900b\}), with repetition rates up to about 35 per second. He did not present quantitative results, but said that the greatest displacements appeared to occur at the manubrium and in the posterior superior quadrant. These observations seem to be at variance with his statement in another paper ( $\{$ Lucae, 1900a $\}$ ) that the motions of the manubrium are smaller than those of the drum itself, in agreement with Helmholtz' principles, but he did not elaborate. Note that Lucae's observations were made on waking patients.

Mechanical probe. $\{$ Mader (1900)\} used a mechano-electrical probe to study eardrum vibration. In response to tones of $240 \mathrm{~Hz}$ and $600 \mathrm{~Hz}$, as well as to a pulse of unspecified duration and shape, Mader found the greatest amplitude to be in the posterior inferior quadrant of the human cadaver eardrum. He also used the probe at three points in a line extending downwards from the tip of the manubrium. The probe output was greatest from the inner third and least from the outer third. However, the output from the middle third contained a distortion which he interpreted as indicating large displacements there that were poorly coupled to the probe. Thus, the conclusion is that the greatest drum displacements occur in the posterior inferior quadrant, away from the manubrium. From Mader's published data one cannot calculate either the sound pressures that he used, or the impedance with which his probe loaded the eardrum.

Mirrors. As early as 1874, Kessel suggested observing eardrum and ossicular displacements by fixing tiny mirrors to the surface under question, and using the angle of reflection of a beam of light as a measure of the motion of the mirror. \{Köhler (1910)\} used this method for measuring malleolar displacements but did not investigate the vibration pattern of the drum itself. \{Wada (1924)\} used the method on the eardrum, but published vibration-pattern data only for non-mammalian species.

\{Dahmann $(1929,1930)\}$ used mirrors on human cadaver eardrums, with the stimulus being a static pressure change of about $60 \mathrm{mmHg}$ in each direction, equivalent to about $170 \mathrm{~dB}$ SPL. His only published data consisted of a sketch of the eardrum with superimposed black marks representing the loci of the reflected beams of light from nine different mirrors. The length of each mark is a measure of the angular deflection of that mirror; that is, it is a measure of the slope of the displacement function at that point, with no indication of relative phase. This absence of phase information makes the data ambiguous. \{Wever \& Lawrence (1954\}, pp. 83-85) interpreted Dahmann's results as meaning that the drum did not exhibit amplitude maxima between the periphery and the 
manubrium. \{Dahmann himself however (1930\}, pp. 350-351) interpreted them as meaning that the middle parts had larger displacements than the manubrium, and this interpretation is in fact more reasonable than that of Wever \& Lawrence ( $\{$ Funnell, 1975\}).

Capacitive probe. The next observations of drum vibration patterns were those of $\{$ Békésy (1941)\}, who used a capacitive probe on human cadavers. In his case also, only one illustration of his results was published. His figure indicates that the central portion of the drum underwent almost no bending in the direction perpendicular to the manubrium. However, if one interprets the contour lines in the figure strictly (\{Funnell, 1975\}) they indicate considerable bending of the drum inferior to the manubrial tip. This is not consistent with the usual interpretation of his findings, which is, in his words, that "the whole eardrum except the extreme periphery vibrates as a stiff surface along with the manubrium". My interpretation of his equal-amplitude curves is that the part of the drum inferior to the umbo is stiff in one direction only, and bends quite a bit in the orthogonal direction. This inconsistency is perhaps caused by inaccuracy in his figure: it is noteworthy that the flat portions of the contours are not quite parallel to the rotation axis as drawn, which is most unexpected. Unfortunately, no actual data were given which would permit clarification of his findings.

It is also impossible to decide with certainty whether his observations were made at intensities within the normal operating range of the ear, since he published neither the sound pressures used nor the actual displacements measured. However, he indicated that his probe could measure down to about 10 nm. In his Figure 5-5 (1941) the iso-amplitude contour lines cover a range of 1 to 15 (arbitrary units) so one can guess that the maximum displacement was at least 150 nm. By comparison, \{Tonndorf \& Khanna (1970)\} found a maximal drum displacement of $800 \mathrm{~nm}$ at $121 \mathrm{~dB}$ SPL (at $525 \mathrm{~Hz}$, in human cadaver). On this basis, one can conclude that Békésy's measurements could have been performed at intensities as low as about $110 \mathrm{~dB}$ SPL, which is starting to be uncomfortably loud but is still within the linear range of the middle ear.

Visual observations II. \{Kobrak (1941)\} described the observation of the eardrums of human cadavers using high-speed cinematography, and later $\{(1943)\}$ discussed the use of stroboscopic illumination with both cadavers and living subjects. In neither of these papers did he actually give the results of his observations. In his much later book, \{Kobrak (1959)\} said that "the fold described by Békésy, around which the drum membrane vibrates, was observed" (p. 40). \{Kirikae (1960)\} cited the 1941 paper as having said that the amplitude of the intermediate part of the drum was greater than that of the central and peripheral parts. \{Kobrak (1959\}, p. 40) mentioned a sound intensity of about $110 \mathrm{~dB}$ at $60 \mathrm{~Hz}$, which was "not too unpleasant" and could easily be tolerated by the waking subject. It is not clear whether his intensity measurement was $\mathrm{dB}$ SPL, $\mathrm{dB}$ hearing level, or dB loudness level. $110 \mathrm{~dB} \mathrm{HL}$ at $60 \mathrm{~Hz}$ is equivalent to about $160 \mathrm{~dB}$ SPL; $110 \mathrm{~dB}$ loudness level (i.e., 110 phons) at $60 \mathrm{~Hz}$ is equivalent to 110 - $130 \mathrm{~dB}$ SPL (\{Beranek, 1954\}, Figures 13.9 and 13.10).

$\{$ Perlman (1945)\} used the same stroboscopic method that Kobrak had. No quantitative results were given. He reported that observations on cadavers indicated that the amplitudes of vibration of the anterior and posterior parts were about the same, although observations in the living ear (because of the difficulties involved) seemed to indicate much smaller amplitudes in the anterior part. The greatest amplitude appeared to be "halfway between the umbo and the posterosuperior part of the annulus", and the smallest amplitude was seen on the manubrium. In a later paper $\{(1947)\}$ he simply cited Békésy's results when it came to discussing the vibration pattern of the drum. In $\{1949\}$ he stated that his earlier stroboscopic observations had 'clearly' shown Békésy's 'piston-like' vibration pattern, with, however, 'some additional motion between the umbo and the periphery ... especially in the posterosuperior quadrant'.

\{Guelke \& Keen (1949)\} used a stroboscopic method on human and cat cadavers, and on an anaesthetized cat, and in all cases "it was clearly observed that the maximum vibration ... is at a point about halfway between the umbo and the periphery of the drum."

\{Owada (1959)\} published sketches of his observations of the vibration patterns of the eardrums of the cat and rabbit, observed under stroboscopic illumination at frequencies of 500 to $1000 \mathrm{~Hz}$. In both species the greatest amplitudes were found midway between the manubrium and the periphery, anteriorly and posteriorly 
as well as inferiorly. (He attributed the differences between the two species to differences in the arrangements of the fibres of the drums.) The stimuli were in the range of 100 to 120 phons, equivalent to 100 to $130 \mathrm{~dB}$ SPL (\{Beranek, 1954\}).

$\{$ Kirikae (1960)\} also used microscopy and microphotography under stroboscopic illumination to observe the vibrations of human cadaver eardrums. He used frequencies of 100 to $800 \mathrm{~Hz}$, and loudnesses of 100 to 120 phons (100 to $140 \mathrm{~dB}$ SPL according to \{Beranek, 1954\}). The largest displacements occurred between the manubrium and the periphery, with the displacements in the posterior superior quadrant being larger than those in the other quadrants. Kirikae concurred with Békésy in saying that "the central part vibrates as a rigid cone" ( \{Kirikae, 1960\}, p. 53), but according to his figure this rigid central part is hardly wider than the manubrium itself. Kirikae's published photograph showing the motion of the entire malleus (1960, Figure 53) indicates a medial-to-lateral translation as well as a rotation. Kirikae does not comment on this, but it may well be a result of the large displacements observed. \{Perlman (1945)\} mentioned a "posteromedial displacement of the whole malleus handle".

Recently $\{$ Helms $(1974,1977)\}$ reported the use of a stroboscopic technique on human cadavers, on dogs, rats and guinea pigs, and finally on waking humans, at frequencies up to $1700 \mathrm{~Hz}$. Qualitative vibration patterns were shown for human and dog. The overall pattern in normal ears was that the region of the drum inferior to the umbo vibrated less than the areas anterior and posterior to the manubrium. He presented some preliminary results of a photogrammetric analysis of stereo photographs which produced iso-amplitude contour lines describing the drum's vibration pattern quantitatively.

Holography. \{Khanna (1970)\} reported the first study of eardrum vibrations using laser holography, an interferometric technique which produces complete iso-amplitude contour maps of a vibrating surface. He used time-averaging with a continuous-wave laser, at frequencies from about 400 to $6000 \mathrm{~Hz}$. The sound intensities were adjusted to provide good contour patterns, and were as low as about $90 \mathrm{~dB}$ SPL in some cases.

$\{$ Khanna (1970) $\}$ presented results observed in cat cadaver ears. It was later shown ( $\{$ Khanna \& Tonndorf, 1972 $\})$ that the patterns are not significantly different in live cats. The displacements are smallest near the manubrium and the periphery, and are greatest in the posterior segment of the drum. The same technique was later used to investigate human cadaver ears ( $\{$ Tonndorf \& Khanna, 1972\}). Again the displacements on the manubrium were smaller than those of the surrounding eardrum, and the largest displacements occurred in the posterior segment.

The time-averaging technique has since been used with guinea-pig and human cadavers (\{Ogura \& Kimura, 1974\}; \{Ogura et al., 1974\}; $\{$ Uyemura et al., $1974\}$ ); frog ( $\{$ Ogura et al., 1974\}; \{Mazumdar et al., 1977\}); and locust (\{Michelsen, 1971\}).

To permit the study of transient displacements \{Dancer et al. (1975)\} used a pulsed ruby laser. They observed the response of the guinea-pig drum to impulses similar to those generated by firearms. The type of stimulus makes it difficult to compare the results with other data, but the pattern is roughly symmetrical with the maximal amplitude occurring in the inferior region.

The use of a pulsed laser also offers advantages when used with sinusoidal stimuli: it allows identification of the phase of the vibrations, and can be very insensitive to background movements. A double-pulse technique was used on human cadaver ears by $\{$ Bally (1977)\}, and then on waking humans ( $\{$ Fritze et al. ,1978\}; \{Fritze, 1979\}; \{Bally, 1979\}).

$\{$ Løkberg et al. $(1979,1980)\}$ have used Electronic Speckle-Pattern Interferometry in waking humans. ESPI provides some of the advantages of pulsed holography but uses continuous-wave lasers. 
The in vivo human data published so far are only preliminary, but agree with the results found using cadavers.

Mössbauer technique. \{Manley (1972)\} and \{Manley \& Johnstone (1974)\} applied the Mössbauer technique to the study of the vibrations of the lizard and guinea-pig middle ears. This technique involves placing a very small gamma-ray source on the vibrating structure, and produces a measure of velocity which can then be converted to displacement if the frequency of vibration is known. The sound pressures used were in the range of 85 to $110 \mathrm{~dB}$ SPL.

Manley \& Johnstone investigated eardrum vibrations by measuring displacements at seven points on the drum. They plotted contour lines based on interpolation of these data at three frequencies. Here again, the manubrial displacements were smaller than those of the surrounding eardrum surface. The greatest displacements occurred in the inferior region.

Discussion. The general picture resulting from the experiments discussed above is that, at low frequencies, the displacements of the manubrium are less than those of the surrounding eardrum. In the human and cat the largest displacements are found in the posterior half of the eardrum, while in the guinea pig and rabbit (where the eardrums are very nearly symmetrical) the largest displacements occur in the inferior region.

Békésy's observations are the only ones that do not agree with this general picture. (\{Kirikae $(1960\}$, p. 53) cited \{Stuhlman $(1937,1943)\}$ as having pointed out that "the central part vibrates as a rigid cone". In fact, however, in the 1937 paper Stuhlman did not mention drum vibration patterns at all, and in the 1943 book he just gave some theoretical speculations which in any case were not consistent with Békésy's ideas.) Even in Békésy's results, the inferior region follows the pattern of having an amplitude maximum part-way between the manubrium and the periphery. In the anterior and posterior regions, however, he indicated that the drum displacements were the same as or less than the manubrial ones.

As discussed by $\{$ Tonndorf \& Khanna (1972)\}, it is unlikely that post-mortem changes could account for Békésy's findings: most other observations on human eardrums have also been on cadavers. Nonlinearity also is probably not responsible for Békésy's disagreement: as mentioned above, Békésy's method was probably sensitive enough to permit the use of sound intensities within the linear range of the eardrum. In any case, other workers using very high intensities found vibration patterns similar to the recent low-level ones.

Four other possible factors may be proposed. First, Tonndorf, in the discussion period after the presentation of a paper ( $\{$ Tonndorf $\&$ Khanna, 1971$\}$ ), suggested that the discrepancy may be due to departures of the ear canal and eardrum from the ideal environment for the use of a capacitive probe. The fact that both the canal walls and the drum itself have finite electrical resistances might have a considerable effect on the probe's output, especially since the geometry of the system is so irregular. Since the eardrum itself is not flat, one must also keep in mind the distinction between (1) measuring displacements perpendicular to the surface of the drum, and (2) measuring the displacement components parallel to a fixed axis, as discussed by $\{$ Helms (1977)\} in connection with stereostroboscopic observations.

Second, it is possible that the size of the tip of Békésy's probe was too large to permit reliable determination of the details of the vibration pattern. \{Békésy $(1941\}$, p. 3) mentioned an electrode diameter of $1 \mathrm{~mm}$. The same figure was given in a translation of the article (\{Békésy, 1960\}, p. 55), but the translation also mentioned parenthetically a tip radius of $1 \mathrm{~mm}$. (Békésy found that the probe output was determined by an area of the vibrating surface approximately equal to that of the probe.) Since Békésy gave no details about how many points he measured, or where they were, it is difficult to decide whether his resolution was good enough to differentiate positively between the type of pattern he proposed and that proposed by other workers.

Third, it is known that Békésy's measurements were done on cadavers obtained from a children's hospital (\{Tonndorf \& Khanna, 1972\}, citing a personal 
communication from Békésy), and that he preferred to use the temporal bones of newborns, at least for cochlear studies (\{Békésy, 1960\}, p. 20). In the absence of any mention of the ages of the cadavers used for his eardrum measurements, one can speculate that the drums may have been immature. It is not known how much this might have affected his results, if at all. As discussed above, few details are available concerning the anatomy and function of the developing human eardrum, and it is possible that there is a different mode of vibration in newborns.

Fourth, it is conceivable that Békésy's use of low (unspecified) ambient temperatures, in an attempt to slow down post-mortem changes, could have affected the mechanical properties of the eardrum.

\subsection{Higher-Frequency Vibration Patterns}

\{Békésy (1941)\} stated that above $2400 \mathrm{~Hz}$ "the conical portion of the eardrum loses its stiffness, and the manubrium in its motion lags behind the motion of the adjacent portion of the membrane" (English translation in \{Békésy, 1960\}, p. 102), but no further details were given. \{Fumagalli (1949\}, p. 294) interpreted this as meaning that above $2400 \mathrm{~Hz}$ Békésy had observed drum vibrations like those predicted by Helmholtz, with a smaller amplitude on the manubrium than on the adjacent drum.

The holographic experiments of Khanna \& Tonndorf provided detailed vibration amplitude patterns up to $6 \mathrm{kHz}$. In cat the simple low-frequency vibration pattern is still present at $2.5 \mathrm{kHz}$, but above that it progressively breaks up as the frequency increases, until by 4 or $5 \mathrm{kHz}$ most of the surface of the drum is only very poorly coupled to the manubrium. The details of the vibration patterns vary from animal to animal. \{Tonndorf \& Khanna (1972)\} observed a similar pattern break-up in human cadaver ears, at about the same frequencies. The use of a double-pulse technique has demonstrated phase changes above $2 \mathrm{kHz}(\{$ Bally, $1977\}$; $\{$ Løkberg et al., 1979\}).

The point velocity measurements of $\{$ Manley (1972)\} and of $\{$ Manley \& Johnstone (1974)\} do not provide complete vibration patterns, particularly if the patterns become more complex. Their observations on the guinea-pig eardrum indicate that the basic low-frequency pattern may not be much changed until the frequency is as high as 6 to $8 \mathrm{kHz}$. However, the data of \{Ogura et al. (1974)\} on the guinea pig suggest that the pattern starts to break up between 3 and $4 \mathrm{kHz}$.

\section{DISCUSSION}

\subsection{Theories of Eardrum Function}

The first attempt to synthesize a quantitative theory of eardrum function was that of $\{$ Helmholtz (1869)\}. His 'curved-membrane' hypothesis was elaborated by $\{$ Esser (1947)\}, and independently by $\{$ Guelke \& Keen (1949)\}, but seemed to be refuted by experimental work of $\{$ Békésy (1941) $\}$ and of $\{$ Wever \& Lawrence (1954) $\}$. The 'hinged-plate' model based on Békésy's data seemed quite secure until the holographic measurements of $\{$ Khanna (1970)\} cast serious doubt on it. (An error discovered in Helmholtz' calculations by \{Hartman (1971)\} explained the apparent lack of reproducibility of Helmholtz' experimental work.)

The attempts of Helmholtz and others (including \{Frank, 1923\}; and \{Gran, 1968\}) to formulate a quantitative theory were hampered by the mathematical complexity of the system. However, the availability of powerful digital computers, and the development of sophisticated numerical techniques for structural engineering, have made the problem more tractable ( $\{$ Funnell, 1975\}; \{Funnell \& Laszlo, 1978\}). These new tools have also pointed up the weakness of our present experimental knowledge of eardrum structure and function. 


\subsection{Directions for Future Experimental Work}

More information is required on the anatomy of the eardrum. Specifically, more quantitative data are needed to describe eardrum thickness and three-dimensional curvature, and the distribution and paths of the fibres.

More work is also required to quantify the viscoelastic mechanical properties of the eardrum, and their dependence on position, direction and frequency. The contributions of the different layers of the drum should also be investigated. Recent work on modelling fibrous connective tissue (\{Decraemer $e t$ al., $1980 \mathrm{a}, \mathrm{b}\}$, for example) should help in interpreting the results of such measurements.

As far as measurements of vibration patterns are concerned, there is a need for more extensive observations in different species, and after various interventions in the middle ear such as interruption or fixing of the ossicular chain. Such data would permit much more conclusive modelling of the eardrum and of the middle ear as a whole.

\subsection{Conclusions}

A better knowledge of eardrum properties and behaviour, and the development of better mathematical models of the eardrum, should lead to significant advances in at least two areas: interpretation of the results of impedance audiometry and tympanometry, which are strongly affected by the drum; and the evaluation of methods of corrective middle-ear surgery, especially the design of drum prostheses.

\section{ACKNOWLEDGEMENTS}

This work has been supported by the Medical Research Council of Canada, le Ministère de l'Education du Québec, the McConnell Foundation, and the Macdonald-Stewart Foundation.

\section{REFERENCES}

\section{R. Funnell}

Last modified: Thu, 2008 Jul 10 17:45:43 


\title{
A critical review of experimental observations on eardrum structure and function
}

\author{
W. Robert J. Funnell \& Charles A. Laszlo \\ BioMedical Engineering Unit \& Department of Otolaryngology \\ McGill University \\ Montréal, Québec, Canada H3G 1Y6
}

\section{References}

1. Aitkin, LM, \& Johnstone, BM: Middle-ear function in a monotreme: the echidna (Tachyglossus aculeatus). J. Exp. Zool. 180: 245-250 (1972)

2. Alberti, PW: Patterns of epithelial migration of the tympanic membrane. Ph.D. thesis (Washington University 1963)

3. Alberti, PW: Epithelial migration on the tympanic membrane. J. Laryngol. 78: 808-830 (1964)

4. Bally, Gv: Holographic analysis of tympanic membrane vibrations in human temporal bone preparations using a double pulsed ruby laser system. Applications of Holography and Optical Data Processing, E. Marom \& A.A. Friesem (eds.), Pergamon Press, Oxford, 593-602 (1977)

5. Bally, Gv: Otological investigations in living man using holographic interferometry. Holography in Medicine and Biology, G. von Bally (ed.), SpringerVerlag, Berlin, 198-205 (1979)

6. Békésy, Gv: On the measurement of the amplitude of vibration of the ossicles with a capacitive probe. Akust. Zeitschr. 6: 1-16 [in German] (1941)

7. Békésy, Gv: The structure of the middle ear and the hearing of one's own voice by bone conduction. J. Acoust. Soc. Am. 21: 217-232 (1949)

8. Békésy, Gv: Experiments in Hearing (McGraw-Hill, Toronto 1960)

9. Beranek, LL: Acoustics (McGraw-Hill, Toronto 1954)

10. Boedts, D, \& Kuijpers, W: Epithelial migration on the tympanic membrane. Acta Oto-laryngol. 85: 248-252 (1978)

11. Bowden, REM: Development of the middle ear and external ear in man. Proc. Roy. Soc. Med. 70: $807-815$ (1977)

12. Dahmann, H: On the physiology of hearing: experimental studies on the mechanics of the ossicular chain, as well as on the behaviours of tones and air pressure I. Zeitschr. f. Hals. Nas. Ohrenhlk. 24: 462-498 [in German] (1929)

13. Dahmann, H: On the physiology of hearing: experimental studies on the mechanics of the ossicular chain, as well as on the behaviours of tones and air pressure II-IV. Zeitschr. g. Hals. Nas. Ohrenhlk. 27: 329-368, discussion 398-402 [in German] (1930)

14. Dancer, AL; Franke, RB; Smigielski, P; Albe, F, \& Fagot, H: Holographic interferometry applied to the investigation of tympanic-membrane displacements in guinea pig ears subjected to acoustic impulses. J. Acoust. Soc. Am. 58: 223-228 (1975)

15. Dayhoff, MO: Atlas of Protein Sequence and Structure Vol. 5 (Nat. Biomed. Res. Found., Washington, DC 1972)

16. Decraemer, WF; Maes, MA, \& Vanhuyse, VJ: An elastic stress-strain relation for soft biological tissues based on a structural model. J. Biomech. 13: 
463-468 (1980a)

17. Decraemer, WF; Maes, MA; Vanhuyse, VJ, \& Vanpeperstraete, P: A non-linear viscoelastic constitutive equation for soft biological tissues, based upon a structural model. J. Biomech. 13: 559-564 (1980b)

18. Decraemer, WF: personal communication (1980c)

19. deSa, DJ: Polypoidal organization of aspirated amniotic squamous debris (amnion nodosum) in middle-ear cavity of newborn infants. Arch. Dis. Childhood 52: 148-151 (1977)

20. Diamant, M: Otitis and pneumatisation of the mastoid bone. Acta Oto-laryngol. Suppl. 41: vii + 149 pp. (1940)

21. Esser, MHM: The mechanism of the middle ear: II. The drum. Bull. Math. Biophys. 9: 75-91 (1947)

22. Filogamo, G: On the morphogenesis and architecture of the tympanic membrane. Zeitschr. f. Zellforsch. \& Mikroskop. Anat. A33: 14-39 [in Italian] (1943)

23. Filogamo, G: Recherches sur la structure de la membrane du tympan chez les différents vertébrés. Acta Anat. 7: 248-272 (1949)

24. Fleischer, G: Studies of the skeleton of the auditory organs of mammals, including humans. S\&aumlaut;ugetier. Mitteil. 21: 131-239 [in German] (1973)

25. Fleischer, G: On a mechanical model of a bat's middle ear. J. Auditory Res. Suppl. 3: 1-75 (1974)

26. Fleischer, G: Evolutionary principles of the mammalian middle ear. Adv. Anat. Embryol. Cell Biol. 55: 1-70 (1978)

27. Frank, O: Sound conduction in the ear. Sitzungsber. math.-physikal. Klass. Bayerischen Akad. Wiss. M\&uumlaut;nchen 1923: 11-77 [in German] (1923)

28. Fritze, W; Kreitlow, H, \& Ringer, K: Holographic investigation of the mode of vibration of the human eardrum. Arch. O-R-L 221: 255-259 [in German] (1978)

29. Fritze, W; Kreitlow, H, \& Winter, D: On holographic-interferometric investigations of the membrana tympani (living man). Holography in Medicine and Biology, G. von Bally (ed.), Springer-Verlag, Berlin, 206-211 (1979)

30. Fumagalli, Z: Morphological research on the sound-transmission apparatus. Arch. Ital. Otol. Rinol. Laringol. 60: Suppl. 1, ix + 323 pp [in Italian, captions \& chapter 7 in English also] (1949)

31. Funnell, WRJ: The acoustical impedance of the guinea-pig middle ear and the effects of the middle-ear muscles. M.Eng. thesis (McGill University, Montréal 1972)

32. Funnell, WRJ: A theoretical study of eardrum vibrations using the finite-element method. Ph.D. thesis (McGill University, Montréal 1975, updated 1976)

33. Funnell, WRJ, \& Laszlo, CA: Dependence of middle-ear parameters on body weight in the guinea pig. J. Acoust. Soc. Am. 56: 1551-1553 (1974)

34. Funnell, WRJ, \& Laszlo, CA: Modeling of the cat eardrum as a thin shell using the finite-element method. J. Acoust. Soc. Am. 63: 1461-1467 (1978)

35. Gates, GR; Saunders, JC; Bock, GR; Aitkin, LM, \& Elliott, MA: Peripheral auditory function in the platypus, Ornithorhynchus anatinus. J. Acoust. Soc. Am. 56: 152-156 (1974)

36. Gaudin, EP: On the middle ear of birds. Acta Otolaryngol. 65: 316-326 (1968)

37. Graham, MD; Reams, C, \& Perkins, R: Human tympanic membrane-malleus attachment. Ann. O.R.L. 87: 426-431 (1978)

38. Grahame, R: A method for measuring human skin elasticity in vivo with observations on the effects of age, sex and pregnancy. Clin. Sci. 39: 223-238 (1970)

39. Gran, S: The analytical basis of middle-ear mechanics. A contribution to the application of the acoustical impedance of the ear. Dissertation [in German] (University of Oslo 1968) 
40. Gruber, J: Contributions to the anatomy of the eardrum. Wochenblatt. d.k.k. Gesellschaft d. Aerzte Wien 7: 1-3, 169-173 [in German] (1867)

41. Guelke, R, \& Keen, JA: A study of the vibrations of the tympanic membrane under direct vision, with a new explanation of their physical characteristics. J. Physiol. 110: 226-236 (1949)

42. Harkness, RD: Biological functions of collagen. Biol. Rev. Cambridge Phil. Soc. 36: 399-463 (1961)

43. Hartman, WF: An error in Helmholtz's calculation of the displacement of the tympanic membrane. J. Acoust. Soc. Am. 49: 1317 (1971)

44. Haut, RC, \& Little, RW: The rheological properties of canine anterior cruciate ligaments. J. Biomech. 2: 289-298 (1969)

45. Helmholtz, HLF: The mechanism of the middle-ear ossicles and of the eardrum. Pfl\&uumlaut;gers Arch. f. Physiol. (Bonn) 1: 1-60 [in German] (1869) [transl. by Buck, AH, \& Smith, N (Wood \& Co., New York 1873) and by Hinton J, Publ. New Sydenham Soc. (London) 62: 97-155 (1874)]

46. Helms, J: Mechanics of the middle ear. Acta O-R-L Belg. 28: 581-585 (1974)

47. Helms, J: Experimental and clinical studies on the function of normal, pathological and surgically treated tympanic membranes. Acta Oto-laryngol. Suppl. 350: 1-59 [in German] (1977)

48. Henson, OW Jr.: Some morphological and functional aspects of certain structures of the middle ear in bats and insectivores. Univ. Kansas Sci. Bull. 42: 151-255 (1961)

49. Hopson, JA: The origin of the mammalian middle ear. Am. Zool. 6: 437-450 (1966)

50. Hunt, RM Jr., \& Korth WW: The auditory region of dermoptera: morphology and function relative to other living mammals. J. Morphol. 164: 167-211 (1980)

51. Johnson, FR; McMinn, RMH, \& Atfield, GN: Ultrastructural and biochemical observations on the tympanic membrane. J. Anat. 103: 297-310 (1968)

52. Keith, RW: Middle ear function in neonates. Arch. Otolaryngol. 101: 376-379 (1975)

53. Kessel, J: On the influence of the middle-ear muscles on the displacements and vibrations of the eardrum in the cadaver ear. Arch. Ohrenhlk. 8: 80-92 [in German] (1874)

54. Khanna, SM: A holographic study of tympanic membrane vibrations in cats. Ph. D. thesis (City University of New York 1970)

55. Khanna, SM, \& Tonndorf, J: Middle ear power transfer. Arch. klin. exp. Ohr. Nas. Kehlk. Heilk. 193: 78-88 (1969)

56. Khanna, SM, \& Tonndorf, J: Tympanic membrane vibrations in cats studied by time-averaged holography. J. Acoust. Soc. Am. 51: 1904-1920 (1972)

57. Khanna, SM, \& Tonndorf, J: Tympanic membrane shape determined by moiré topography. J. Acoust. Soc. Am. 57: S72 (abstract) (1975a)

58. Khanna, SM, \& Tonndorf, J: Tympanic membrane: effect of dc pressure changes in the middle ear of cats. J. Acoust. Soc. Am. 58: S88 (abstract) (1975b)

59. Kirikae, I: The structure and function of the middle ear (University of Tokyo Press, Tokyo 1960)

60. Kobrak, HG: A cinematographic study of the conduction of sound in the human ear. J. Acoust. Soc. Am. 13: 179-181 (1941)

61. Kobrak, HG: Direct observations of the acoustic oscillations of the human ear. J. Acoust. Soc. Am. 15: 54-56 (1943)

62. Kobrak, HG: The middle ear (University of Chicago Press 1959)

63. K\&oumlaut;hler, W: Acoustical studies I. Zeitschr. f. Psychol. 54: 241-289 (1910)

64. Kojo, Y: Morphological studies of the human tympanic membrane. J. O.-R.-L. Soc. Japan 57: 115-126 [in Japanese] (1954) 
65. Lay, DM: The anatomy, physiology, functional significance and evolution of specialized hearing organs of gerbilline rodents. J. Morph. 138: 41-120 (1972)

66. Lim, DJ: Tympanic membrane. Electron microscopic observations. Part I. Pars tensa. Acta Otolaryngol. 66: 181-198 (1968a)

67. Lim, DJ: Tympanic membrane. Part II. Pars flaccida. Acta Otolaryngol. 66: 515-532 (1968b)

68. Lim, DJ: Human tympanic membrane. An ultrastructural observation. Acta Otolaryngol. 70: 176-186 (1970)

69. Litton, WB: Epidermal migration in the ear: the location and characteristics of the generation centre revealed by utilizing a radioactive desoxyribose nucleic acid precursor. Acta Otolaryngol. Suppl. 240: 1-39 (1968)

70. Løkberg, OJ; Høgmoen, K, \& Gundersen, T: Use of ESPI to measure the vibration of the human eardrum in vivo and other biological movements. Holography in Medicine and Biology, G. von Bally (ed.), Springer-Verlag, Berlin, 212-217 (1979)

71. Løkberg, OJ; Høgmoen, K, \& Gundersen, T: Vibration measurement of the human tympanic membrane in vivo. Acta Oto-laryngol. 89: 37-42 (1980)

72. Longo, AV: Histologic survey of the human tympanic annulus and sulcus. M.Sc. thesis (State University of Iowa 1962)

73. Lucae, A: Vibratory massage in the treatment of progressive deafness, with especial consideration of my elastic pressure probe. Laryngoscope 9: 157-168 (1900a)

74. Lucae, A: Critical review and new results concerning vibration massage of the ear. Arch. f. Ohrenhlk. 51: 1-18 [in German] (1900b)

75. Lucae, A: The otostroboscope and its physiological diagnostic significance. Arch. f. Ohrenhlk. 53: 39-51 [in German] (1901)

76. Lynch, TJ, III; Nedzelnitsky, V, \& Peake, WT: Measurements of acoustic input impedance of the cochlea in cats. J. Acoust. Soc. Am. 59: S30 (abstract) (1976)

77. Lynch, TJ, III: Signal processing by the cat middle ear: admittance and transmission, measurements and models. Ph.D. thesis, Mass. Inst. Technol., 257 pp (1981)

78. Mach, E, \& Kessel, J: Studies on the topography and mechanics of the middle ear. SitzBer. Math.-Naturw. Cl. Kaiser. Akad. Wiss. (Wien) 3 69: 221-243 [in German] (1874)

79. Mader, L: Microphonic studies of the sound-conducting apparatus of the human ear. SitzBer. Math.-Naturw. Cl. Kaiser. Akad. Wiss. (Wien) 3 109: $37-75$ [in German] (1900) [abstract in Laryngoscope 9: 371 (1900)]

80. Magnoni, A: Migration of epithelium of tympanic membrane. Valsalva 14: 234-240 (1938)

81. Manley, GA: The middle ear of the Tokay Gecko. J. Comp. Physiol. 81: 239-250 (1972)

82. Manley, GA, \& Johnstone, BM: Middle-ear function in the guinea pig. J. Acoust. Soc. Am. 56: $571-576$ (1974)

83. Mazumdar, J; Bucco, D, \& Hansen, C: Time-averaged holography for the study of the vibrations of the tympanic membrane in frog cadaver. J. Oto-Laryngol. Soc. Australia 4: 149-154 (1977)

84. McMinn, RMH, \& Taylor, M: Ultrastructure of fibrils in developing human and guinea-pig tympanic membrane. J. Anat. 125: 107-115 (1978)

85. Michelsen, A: The physiology of the locust ear. Zeitschr. vergl. Physiol. 71: 49-128 (1971)

86. Michelsen, A, \& Larsen, ON: Biophysics of Ensiferan ear. 1. Tympanal vibrations in bushcrickets (Tettigoniidae) studied with laser vibrometry. J. Comp. Physiol. A 123: 193-203 (1978)

87. Mikaelian, D, \& Ruben, RJ: Development of hearing in the normal CBA-J mouse. Acta Otolaryngol. 59: 451-461 (1965) 
88. Mundie, JR: The impedance of the ear -- a variable quantity. U.S. Army Med. Res. Lab. Report No. 576: 63-85 (1963) [abstract in J. Acoust. Soc. Am. 34: $721(1962)]$

89. Oaks, ECJ: Structure and function of inflated middle ears of rodents. Ph. D. thesis (Yale University, New Haven 1967)

90. Ogura, Y, \& Kimura, Y: Vibration analysis of the human eardrum by holographic interferometry. Rinsho-Jika (Clin. Otol.) 1: 10-11 [in Japanese] (1974)

91. Ogura, Y, et al.: A holographic study of eardrum vibrations. Jibi-inkoka (Otolaryngol.) 46: 83-88 [in Japanese] (1974)

92. Onchi, Y: Mechanism of the middle ear. J. Acoust. Soc. Am. 33: 794-805 (1961)

93. Owada, I: Fibrous structure of the tympanic membrane in vertebrates. J. Otorhinolaryngol. Soc. Japan 62: 28-43 [in Japanese] (1959)

94. Peake, WT, \& Guinan, JJ Jr: A circuit model for the cat's middle ear. M.I.T. Lab. Electron. Q. Prog. Report 84: 320-326 (1967)

95. Perlman, HB: Stroboscopic examination of the ear. Ann. O.R.L. 54: 483-494 (1945)

96. Perlman, HB: Some physical properties of the conduction apparatus. Ann. O.R.L. 56: 334-346 (1947)

97. Perlman, HB: Some physical problems in conduction deafness. Ann. O.R.L. 58: 86-110 (1949)

98. Peterson, EA; Levison, M; Lovett, S; Feng, A, \& Dunn, SH: The relationship between middle ear morphology and peripheral auditory function in rodents, I: Sciuridae. J. Aud. Res. 14: 227-242 (1974)

99. Politzer, A: The anatomical and histological dissection of the human ear in the normal and diseased condition (Enke, Stuttgart 1889) [in German, transl. by Stone G (Baillière, Tindall \& Cox, Strand 1892)]

100. Reijnen, CJH, \& Kuijpers, W: The healing pattern of the drum membrane. Acta Otolaryngol. Suppl. 287: 1-74 (1971)

101. Relkin, EM; Saunders, JC, \& Konkle, DF: The development of middle-ear admittance in the hamster. J. Acoust. Soc. Am. 66: 133-139 (1979)

102. Relkin, EM, \& Saunders, JC: Displacement of the malleus in neonatal golden hamsters. Acta Otolaryngol. 90: 6-15 (1980)

103. Ruttin, E: External and internal ligaments of the tympanic membrane. Anat. Anz. 54: 433-435 [in German] (1921)

104. Saunders, JC: personal communication (1981)

105. Shimada, T, \& Lim, DJ: The fiber arrangement of the human tympanic membrane: a scanning electron microscopic observation. Ann. O.R.L. 80: 210-217 (1971)

106. Snowdon, JC: Vibration and shock in damped mechanical systems (Wiley, New York 1968)

107. Stenzel, KH; Miyata, T, \& Rubin, AL: Collagen as a biomaterial. Ann. Rev. Biophys. Bioeng. 3: 231-253 (1974)

108. Stuhlman, O Jr: The nonlinear transmission characteristics of the auditory ossicles. J. Acoust. Soc. Am. 9: 119-128 (1937)

109. Stuhlman, O Jr: An introduction to biophysics (Wiley, New York 1943)

110. Taguchi, K; Picton, TW; Orpin, JA, and Goodman, WS: Evoked response audiometry in newborn infants. Acta Oto-laryngol. Suppl. 252: 5-17 (1969)

111. Tonndorf, J, \& Khanna, SM: The role of the tympanic membrane in middle ear transmission. Ann. O.R.L. 79: 743-753 (1970)

112. Tonndorf, J, \& Khanna, SM: Validation of holographic observations on the displacement of the tympanic membrane in cats. J. Acoust. Soc. Am. 50: 92 (abstract) (1971)

113. Tonndorf, J, \& Khanna, SM: Tympanic-membrane vibrations in human cadaver ears studied by time-averaged holography. J. Acoust. Soc. Am. 52: 


\section{1-1233 (1972)}

114. Tonndorf, J; Khanna, SM, \& Greenfield, EC: The function of reconstructed tympanic membranes in cats. Ann. Otol. Rhinol. Laryngol. 80: 861-870 (1971)

115. Tonndorf, J; Khanna, SM, \& Greenfield, EC: Total myringoplasty: functional aspects. Acta Otolaryngol. 73: 87-93 (1972)

116. Uyemura, T; Yamamoto, Y; Udagawa, T; Ogura, Y, \& Kimura, Y: Vibration analysis by holographic interferometry (vibration mode of the tympanic membrane). Bull. Japan Soc. Prec. Eng. 8: 25-26 (1974)

117. Wada, Y: Contribution to the comparative physiology of the ear. Pfl\&uumlaut;gers Arch. ges. Physiol. 202: 46-69 [in German] (1924)

118. Webster, DB: Ear structure and function in modern mammals. Am. Zool. 6: 451-466 (1966)

119. Webster, DB: Auditory systems of Heteromyidae: postnatal development of the ear of Dipodomys merriami. J. Morph. 146: 377-394 (1975)

120. Webster, DB, \& Webster, M: Auditory systems of Heteromyidae: functional morphology and evolution of the middle ear. J. Morph. 146: 343-376 (1975)

121. Wever, EG, \& Lawrence, M: Physiological acoustics (Princeton University Press, Princeton 1954)

122. Wilber, LA: Anatomy and physiology of the middle ear. Chapter 3 in Feldman, AS, \& Wilber, LA: Acoustic impedance and admittance: Measurement of middle ear function (Williams \& Wilkins, Baltimore 1976)

123. Wilkes, GL; Brown, IA, \& Wildnauer, RH: The biomechanical properties of skin. CRC Crit. Rev. Bioeng. 1: $453-495$ (1973)

124. Witnauer, LP, \& Palm, WE: Preliminary studies of dynamic mechanical properties of leather. Am. Leather Chemists' Ass. J. 56: 58-67 (1961)

125. Zanzucchi, G: Modification of the elastic fibres of the tympanic membrane at various ages. Arch. Ital. Otol. 50: 203-221 [in Italian] (1938)

126. Zwislocki, J: Analysis of the middle ear function. Part I. Input impedance. J. Acoust. Soc. Am. 34: 1514-1523 (1962)

127. Zwislocki, J: Analysis of the middle ear function. Part II. Guinea-pig ear. J. Acoust. Soc. Am. 35: 1034-1040 (1963) 